\title{
Modelo matemático de tratamento de câncer via quimioterapia em ciclos
}

\author{
Rafael Trevisanuto Guiraldello* \\ Programa de Mestrado em Biometria, IBB, UNESP, \\ 18618-970, Botucatu, SP \\ E-mail: trevi@ibb.unesp.br \\ Fernando Luiz Pio dos Santos \\ Paulo Fernando de Arruda Mancera ${ }^{\dagger}$ \\ Departamento de Bioestatística, IBB, UNESP, \\ 18618-970, Botucatu, SP \\ E-mail: flpio@ibb.unesp.br, pmancera@ibb.unesp.br.
}

\section{RESUMO}

Câncer é uma doença muito séria e afeta uma parcela considerável da população, tendo a perspectiva que num futuro não muito distante, será a primeira causa de morte prematura no ocidente, deixando para trás as doenças cardiovasculares. De acordo com o Instituto Nacional do Câncer, a estimativa para o ano de 2014, que será válida também para o ano de 2015, aponta para a ocorrência de aproximadamente 576 mil casos novos de câncer [3]. Os tipos mais incidentes, à exceção do câncer de pele do tipo não melanoma, serão os cânceres de próstata, pulmão, cólon e reto, estômago e cavidade oral no sexo masculino e os cânceres de mama, cólon e reto, colo do útero, pulmão e glândula tireoide no sexo feminino, acompanhando o mesmo perfil da magnitude observada no mundo.

Neste trabalho apresentamos um modelo de equações diferenciais parciais que descreve o crescimento de tumores sólidos com tratamento quimioterápico.

Palavras-chave: Modelagem Matemática, Tumor, Quimioterapia.

\section{Modelo Matemático}

Baseado em [2], propomos o seguinte modelo:

$$
\left\{\begin{array}{l}
\frac{\partial N_{1}}{\partial t}=P_{1} \Delta N_{1}+r_{1} N_{1}\left(1-\frac{N_{1}}{k_{1}+L_{1}}\right)-\alpha_{12} \frac{r_{1}}{k_{1}+L_{1}} N_{1} N_{2}-N_{1} \mu \frac{Q}{a+Q} \\
\frac{\partial N_{2}}{\partial t}=P_{2} \Delta N_{2}+r_{2} N_{2}\left(1-\frac{N_{2}}{k_{2}}\right)-\alpha_{21} \frac{r_{2}}{k_{2}} N_{1} N_{2}-N_{2} \nu \frac{Q}{b+Q} \\
\frac{\partial L_{1}}{\partial t}=D_{1} \Delta L_{1}+\sigma L_{1}\left(1-\frac{L_{1}}{k_{2}}\right)-\alpha_{3} \frac{\sigma}{k_{2}} N_{1} L_{1}-\eta \frac{L_{1} Q}{c+Q}-\nabla \cdot\left(\frac{\chi L_{1}}{k_{2}+N_{1}} \nabla N_{1}\right) \\
\frac{\partial Q}{\partial t}=P_{3} \Delta Q+q-\lambda Q
\end{array}\right.
$$

em que $N_{1}, N_{2}, L_{1}$ e $Q$ denotam a densidade de células tumorais, células normas, células endoteliais e droga quimioterápica, respectivamente. Os parâmetros $r_{1}, r_{2}$ e $\sigma$ são as taxas de crescimento associadas

\footnotetext{
${ }^{*}$ Bolsita CAPES.

${ }^{\dagger}$ FAPESP (13/08133-0, 09/15098-0) e FUNDUNESP (1886/009/13-PROPe/CDC).
} 
a $N_{1}, N_{2}$ e $L_{1} ; \alpha_{i j}$ sãos os coeficientes de competição de $N_{j}$ com $N_{i} ; q(t) \geq 0$ é o fluxo de infusão e $\lambda$ a taxa de decaimento da droga quimioterápica; $k_{1}$ é a capacidade suporte inicial do tumor e $k_{2}$ a capacidade suporte de células normais; $\alpha_{3}$ modela a liberação de TIF pelo tumor; $\mu, \nu$ e $\eta$ são as taxas de mortalidade de $N_{1}, N_{2}$ e $L_{1}$ devido a quimioterapia; $a, b$ e $c$ são densidades de quimioterápico que ditam o efeito de $Q$ em $N_{1}, N_{2}$ e $L_{1} ; P_{1}, P_{2}, D_{1}$ e $P_{3}$ são os coeficientes de difusão de $N_{1}, N_{2}, L_{1}$ e $Q$; $\chi$ é o coeficiente de quimiotaxia de $L_{1}[1]$.

As condições iniciais para densidades, bem como as condições de fronteira no domínio $\partial \Omega$ são dadas, respectivamente, por

$$
\begin{gathered}
N_{1}(0, x)=10^{-5} \mathrm{e}^{-20\|x-0.5\|^{2}}, N_{2}(0, x)=1-N_{1}, L_{1}(0, x)=10^{-4} \mathrm{e}^{-20\|x-0.5\|^{2}} \Omega . \\
\frac{\partial N_{i}}{\partial n}=\frac{\partial Q}{\partial n}=\frac{\partial L_{1}}{\partial n}=0, \partial \Omega, i=1,2, \ldots
\end{gathered}
$$

\section{Resultados}
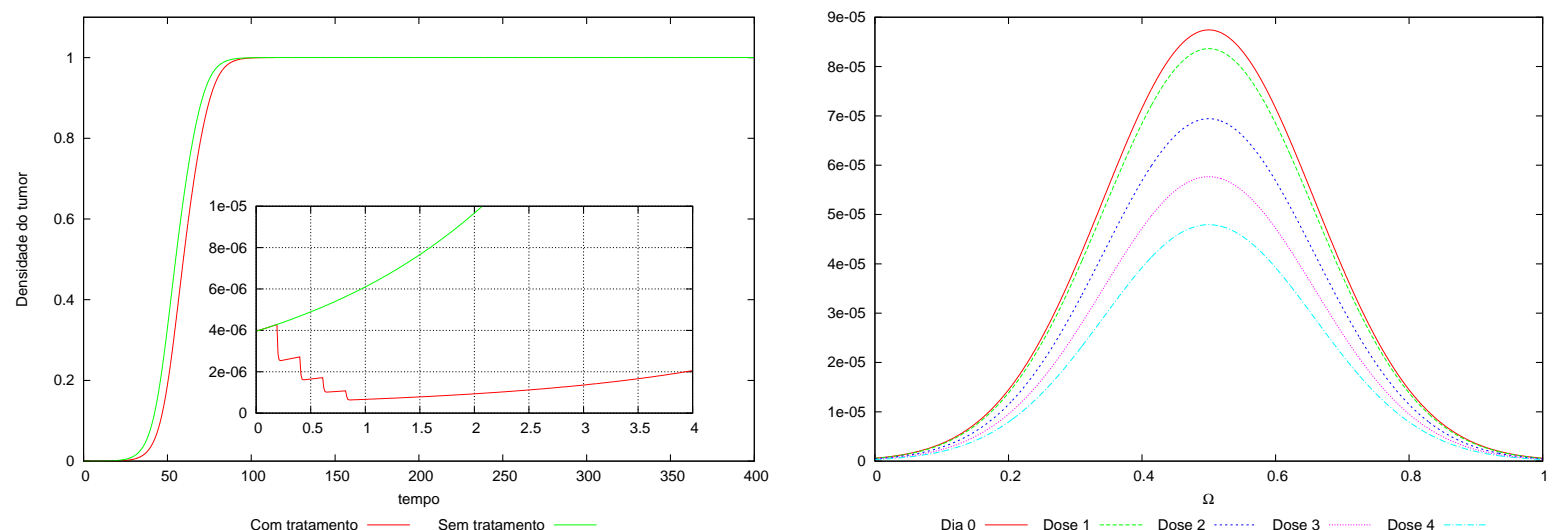

Figura 1: Na figura à esquerda apresentamos a densidade tumoral em função do tempo. A linha em verde representa a evolução da densidade do tumor sem tratamento e a linha em vermelho representa a evolução com tratamento. Na figura à direita, a curva mais externa representa espacialmente a densidade do tumor antes do tratamento e as próximas curvas são as densidades após a infusão do quimioterápico que ocorre a cada 21 dias.(adimensional)

\section{Conclusões}

Construímos um modelo com base em [2], com o propósito de entender como o quimioterápico se difundirá pelo tumor com o passar do tempo. Através de simulação numérica apresentamos um cenário do comportamento do crescimento do tumor perante difusão e quimioterapia.

\section{Referências}

[1] A.R.A. Anderson and M.A.J. Chaplain, Continuous and discrete mathematical models of tumourinduced angiogenesis, Bull. Math Biol., 60 (1998), 857-899.

[2] D.S. Rodrigues, P.F.A. Mancera, Mathematical analysis and simulations involving chemotherapy and surgery on large human tumours under a suitable cell-kill functional response, Math Biosc Eng, 10:1 (2013), 221-234

[3] http://www.inca.gov.br/estimativa/2014/index.asp?ID=2. Acessado em 17/02/2014. 